УДК 631.873 .3

\title{
ОСОБЕННОСТИ МИНЕРАЛЬНОГО СОСТАВА БУРЫХ ВОДОРОСЛЕЙ БЕЛОГО И БАРЕНЦЕВА МОРЕЙ
}

\author{
() К.Г. Боголицын ${ }^{1,2}$, П.А. Каплицин ${ }^{l^{*}}$, Е.М. Кашина ${ }^{1,3}$, Н.Л. Иванченко ${ }^{1,3}$, Н.М. Кокрятская ${ }^{2}$, \\ Д.В. Овчинников ${ }^{1,3}$ \\ ${ }^{1}$ Северный (Арктический) фредеральный университет им. М.В. Ломоносова, \\ наб. Северной Двины, 17, Архангельск, 163002 (Россия), e-mail: tph@agtu.ru \\ ${ }^{2}$ Институт экологических проблем Севера УрО РАН, наб. Северной Двины, 23, \\ Архангельск,163002 (Россия), e-mail: dirnauka@iepn.ru \\ ${ }^{3}$ Центр коллективного пользованием научным оборудованием «Арктика», \\ ул. Северодвинская, 14, Архангельск, 163002 (Россия), e-mail: a.kozhevnikov@agtu.ru
}

Проанализировано содержание макро (Mg, $\mathrm{Na}, \mathrm{Ca}, \mathrm{K}, \mathrm{Cl}, \mathrm{S})$ и микроэлементов (I, Br, Fe, Cr, Ti, P, Si, Sr, Zn, Cu, $\mathrm{Al})$, а также токсичных тяжелых металлов (Pb, Hg) в 25 образцах четырех бурых водорослей (Laminaria saccharina (Linnaeus) J.V.Lamouroux, Laminaria digitata (Hudson) J.V.Lamouroux, Fucus vesiculosus Linnaeus, Ascophyllum nodosum (Linnaeus) Le Jolis), отобранных в ходе комплексной научно-исследовательской экспедиции «Арктический плавучий университет 2012» в Белом и Баренцевом морях. Сделаны выводы о более выраженной взаимосвязи накопления элементов бурыми водорослями в зависимости от семейства, чем от условий произрастания, а также о незагрязненности акваторий Белого и Баренцева морей ртутью и свинцом.

Ключевые слова: бурые водоросли, макроэлементы, микроэлементы, тяжелые металлы.

Работа выполнена с использованием оборудования ЦКП НО «Арктика» Северного (Арктического) федерального университета имени М.В. Ломоносова при финансовой поддержке Министерства образования и науки РФ.

\section{Введение}

Бурые водоросли богаты полисахаридами, белками, витаминами, макро- и микроэлементами, а также пигментами и жирными кислотами $[1,2]$. Они содержат не просто почти все незаменимые для человека

Боголицын Константин Григорьевич - проректор по научной работе Северного (Арктического) федерального университета им. М.В. Ломоносова, директор Института экологических проблем Севера УрО РАН, заведующий кафедрой теоретической и прикладной химии, доктор химических наук, профессор, тел.: (8182) 28-76-36,

e-mail: bogolitsyn@agtu.ru

Каплицин Платон Александрович - аспирант, e-mail: platonkaplicin@yandex.ru

Кашина Евгения Михайловна - ассистент

Иванченко Николай Леонидович - старший научный сотрудник, кандидат химических наук,

e-mail: a.kozhevnikov@agtu.ru

Кокрятская Наталья Михайловна - старший научный сотрудник, кандидат геолого-минералогических наук, e-mail: labecoarh@iepn.ru

Овчинников Денис Владимирович - младший научный сотрудник, e-mail: a.kozhevnikov@agtu.ru вещества, но и нередко в гораздо больших количествах, чем в овощах и других наземных растениях [3]. Водоросли вполне могут удовлетворять потребности человека в полноценной пище и быть полезны для здоровья $[4,5]$. Водоросли содержат большое количество необходимых для человека макро- и микроэлементов [6], что обусловлено высокой зольностью, значение которой в некоторых случаях может достигать 50\% [2]. Для сравнения, наземные растения содержат лишь 5-10\% золы [6].

Несмотря на наличие в водорослях большого количества полезных веществ, не стоит забывать о том, что они концентрируют в своих тканях не только полезные микро- и макроэлементы, но и токсичные тяжелые металлы. Тяжелыми металлами по определе-

\footnotetext{
* Автор, с которым следует вести переписку.
} 
нию являются элементы с атомной массой в 5 и более раз больше, чем у воды, они токсичны даже при низких концентрациях [7]. Многие тяжелые металлы присутствуют в окружающей среде в очень низких концентрациях, и это является естественным фоном, в то время как превышение естественного фона чаще всего является следствием человеческой активности $[7,8]$. Одними из наиболее часто встречающихся и опасных тяжелых металлов являются свинец и ртуть. Накопление их в человеческом организме может привести к тяжелым заболеваниям или даже смерти [8]. Способность к накоплению тяжелых металлов делает бурые водоросли хорошим биоиндикатором загрязнения акваторий, в которых они произрастают [9-16]. В Арктических морях особые условия, как климатические, так и с точки зрения антропогенного воздействия. Необходимо исследовать взаимосвязь между показателями воды и составом водорослей.

Целью данной работы является определение закономерностей накопления различных элементов водорослями в зависимости от вида и места произрастания, а также оценка бурых водорослей как источника ценных минеральных веществ и оценка содержания в них токсичных тяжелых металлов.

\section{Экспериментальная часть}

Объектом исследований послужили 25 образцов 4 видов бурых водорослей (2 вида ламинариевых (Laminaria saccharina и Laminaria digitata) и 2 - фукусовых (Fucus vesiculosus и Ascophyllum nodosum)), отобранных в ходе комплексной научно-исследовательской экспедиции «Арктический плавучий университет 2012» на 3 точках в акватории Белого моря (рис. 1б) и 5 точках в акватории Баренцева моря (рис. $1 a$ ) с 11 июня по 6 июля 2012 г. При отсутствии атмосферных осадков пробы сушились до воздушно-сухого состояния на открытом воздухе в течение суток. В пасмурную погоду пробы высушивались в лабораторных условиях в течение не менее трех суток, поддерживая повышенную температуру в помещении с помощью электрической тепловой пушки (температура $40{ }^{\circ} \mathrm{C}$ ).

a)

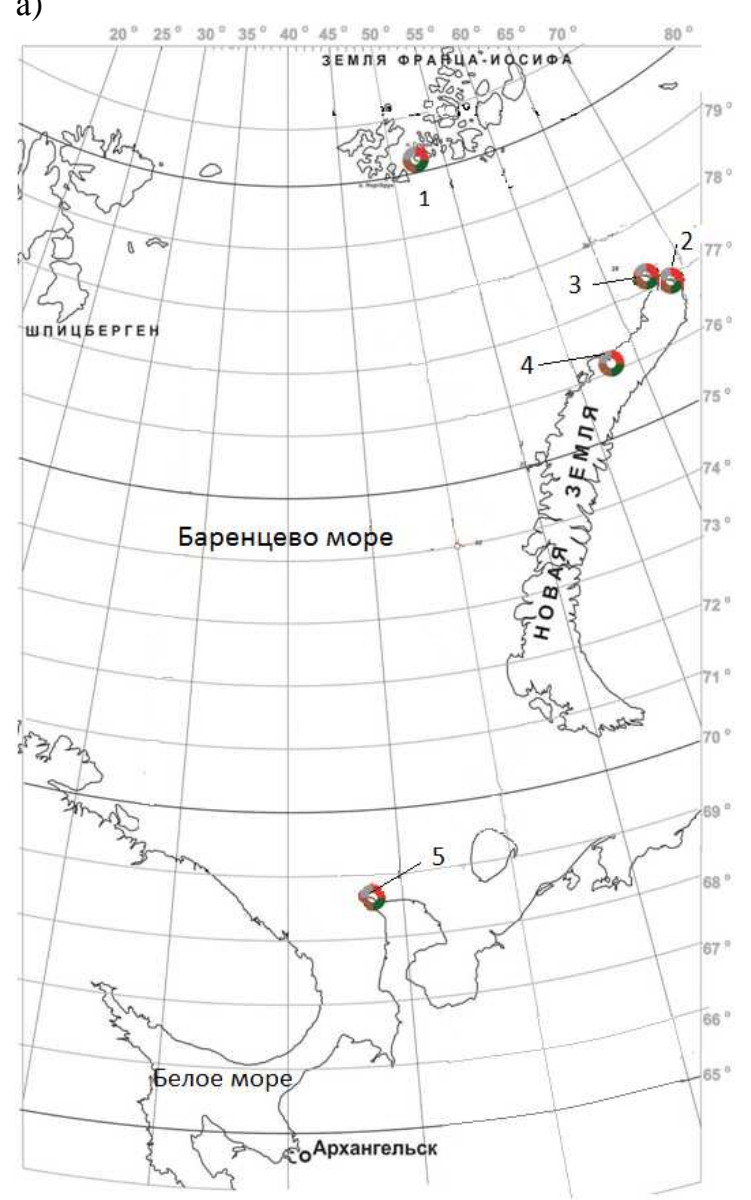

б)

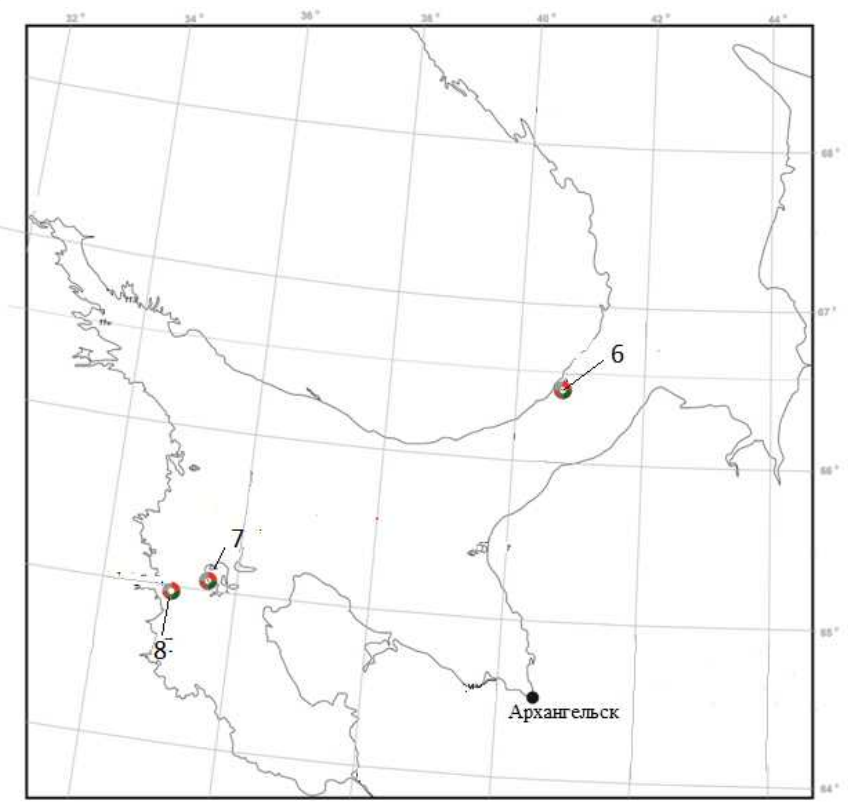

Рис. 1. Карта отбора проб бурых водорослей:

в Баренцевом море (a), Белом море (б). 1 - остров Скотт-Келти; 2 - мыс Желания; 3 - Оранские острова; 4 - залив Русская Гавань; 5 - мыс Канин Нос; 6 - остров Сосновец; 7 - остров Большой Соловецкий; 8 - остров Русский Кузов 
Размол водорослей проводился с использованием планетарной шаровой мельницы Retsch PM100*) в течение 1 мин, при скорости вращения ротора 400 мин $^{-1}$. Качественный и количественный минеральный состав биомассы водорослей был исследован методом рентгенофлуоресцентного анализа на волнодисперсионном рентгенофлуорисцентном спектрофотометре XRF-1800*) по результатам двух параллельных определений, с коэффициентом вариации не более 6\%. Условия определения: напряжение 40кВ, сила тока 95мА, лампа с родиевым анодом, с использованием кристаллов анализаторов LiF, Ge, PET, TAP; детекторы сцинтилляционный и полупроводниковый, экспликация 40 с, в атмосфере вакуума. Концентрация ртути определялась методом атомной адсорбции (метод холодного пара), на атомно-адсорбционном спектрометpe Mercury AA Analitic Jena по стандартной методике [17]. При определении зольности и влажности образцов использовалась стандартная методика [18].

В точках отбора проб водорослей определялись термохалинные характеристики воды (температура и соленость), а так же содержание основных катионов. Для производства океанографических измерений и отбора проб воды для последующего гидрохимического анализа использовался комплекс SBE 32c, оснащенный 12 батометрами емкостью 5 литров, и CTD Зонд SBE 19 plus для измерения температуры, давления и электропроводности (соленость) морской воды. Содержание основных катионов (натрия, магния, кальция, калия, аммония) в морской воде определялось методом капиллярного зонного электрофореза с использованием системы капиллярного электрофореза Agilent 7100 [19].

Определение биогенных элементов в морской воде проводилось фотометрическим методом на однолучевом спектрофотометре СПЕКОЛ 1300 (UV VIS Spectrophotometer SPEKOL 1300). Анализ морской воды на содержание кремния проводился по РД 52.10.744-2010 [20]. Показатель точности (границы погрешности при вероятности $\mathrm{P}=0,95)$ рассчитывается по зависимостям, приведенным в методике: $0,04+$ $1,65 \mathrm{X}$, где X изменяется в диапазоне от 10,0 до 1200 мкг/дм ${ }^{3}$. Анализ морской воды на содержание фосфатов проводился по РД 52.10.738-2010 [21]. Показатель точности (границы погрешности при вероятности $\mathrm{P}=0,95)$ рассчитывается по зависимостям, приведенным в методике: $0,32+0,08 \mathrm{X}$, где Х изменяется в диапазоне от 5,00 до 100,00 мкг/дм³ . Анализ морской воды на содержание азота нитритного проводился по РД 52.10.740-2010 [22]. Показатель точности (границы погрешности при вероятности $\mathrm{P}=0,95$ ) рассчитывается по зависимостям, приведенным в методике: $0,08+0,06 \mathrm{X}$, где X изменяется в диапазоне от 0,50 до 100000 мкг/дм³ . Определение рН выполнялось в соответствии с РД 52.10.735-2010 [23].

\section{Результаты и обсуждение}

Основными факторами, влияющими на содержание минеральных элементов в водорослях, являются гидрологические, гидрохимические и гидродинамические параметры состояния вод, а также широта района произрастания, определяющая длину дня и температурный режим вод [2]. Так, произрастание водорослей в зонах опреснения воды ведет к снижению уровня накопления солей в тканях из-за их выщелачивания. Растения, развивающиеся в сублиторали, всегда содержат больше солей, чем растущие на литорали.

Солёность (общая минерализация) является одной из основных характеристик водных масс. Особую роль она играет в формировании биологической продуктивности морей и океанов, так как многие организмы очень восприимчивы к ее незначительным изменениям. Исходя из этого очень важно знать гидрохимические особенности точек отбора проб макрофитов (табл. 1).

Таблица 1. Характеристика поверхностных вод в точках отбора проб водорослей в Белом и Баренцевом морях

\begin{tabular}{|c|c|c|c|c|c|c|c|c|c|}
\hline Точка отбора & $\begin{array}{c}\text { Соле- } \\
\text { ность, \%о }\end{array}$ & $\mathrm{pH}$ & $\mathrm{Na}$, г/л & $\mathrm{Mg}$, г/л & $\mathrm{K}$, г/л & $\mathrm{Ca}$, г/л & $\begin{array}{l}\mathrm{NO}_{2}, \\
\text { мКг/л }\end{array}$ & $\begin{array}{c}\mathrm{Si}\left(\mathrm{Si}_{2} \mathrm{O}_{4}\right), \\
\text { мКг/л }\end{array}$ & $\begin{array}{c}\mathrm{P}\left(\mathrm{PO}_{4}\right), \\
\text { мкг/л }\end{array}$ \\
\hline \multicolumn{10}{|c|}{ Баренцево море } \\
\hline Остров Скотт-келти & 33,1 & 8,42 & - & - & - & - & H.O & 22,16 & 3,25 \\
\hline Мыс Желания & 34,2 & 8,23 & - & - & - & - & H.O & 14,22 & - \\
\hline Залив Русская Гавань & 34,5 & 8,28 & 7,50 & 0,77 & 0,25 & 0,33 & 0,29 & 27,32 & 6,50 \\
\hline Оранские острова & 34,3 & 8,30 & 9,60 & 1,09 & 0,37 & 0,41 & 0,09 & 38,42 & 10,35 \\
\hline Мыс Канин Нос*) & 29,1 & 8,26 & 12,50 & 1,50 & 0,56 & 0,58 & 1,73 & 90,65 & 3,46 \\
\hline \multicolumn{10}{|c|}{ Белое море } \\
\hline Остров Сосновец* & 28,9 & 8,17 & 8,80 & 1,01 & 0,36 & 0,28 & H.O & - & - \\
\hline Остров Большой Соловецкий & 25,0 & 8,12 & 6,70 & 0,75 & 0,30 & 0,17 & H.O & - & - \\
\hline Остров Русский Кузов & 23,8 & 8,11 & 8,90 & 0,96 & 0,45 & 0,37 & 0,29 & - & - \\
\hline
\end{tabular}

* точки являются зонами смешения водных масс Белого и Баренцева моря 
Соленость водных масс Баренцева моря значительно отличается от солености водной массы Белого моря, на которую сильное опресняющее воздействие оказывает континентальный сток. Следовательно, в этих морях создаются различные условия, определяющие рост и развития водорослей. Исходя из этого мы можем проследить зависимость между соленостью воды и массовой долей минеральных веществ в водорослях (табл. 2).

Для ламинариевых водорослей очевидна тенденция к увеличению содержания минеральных веществ с увеличением солености воды (табл. 2). Для Fucus vesiculosus такая тенденция не прослеживается, возможно, из-за особенностей произрастания в литоральной зоне [24]. Содержание минеральных веществ в биомассе ламинариевых водорослей значительно выше, чем в фукусовых, - 23,1-43,2\% и 20,9-25,1\% соответственно (табл. 3). При этом наибольшая зольность у ламинариевых водорослей наблюдается в самых северных точках отбора проб (остров Скотт-Келти архипелага Земля Франца-Иосифа) и в горле Белого моря (остров Сосновец), где значения зольности в среднем 40\%. Из ламинариевых водорослей к накоплению минеральных веществ более подвержена Laminaria digitata.

Макрофиты содержат почти все элементы, распространенные в морской воде. Их соотношения в водорослях значительно варьируются у различных видов. Водоросли обладают избирательной кумулятивной способностью, в результате чего в их слоевищах накапливается разнообразный комплекс микроэлементов, причем концентрация некоторых из них в тканях в десятки (кальций), сотни (бром, хром) и тысячи (йод, цинк, барий) раз превышает их содержание в морской воде [1]. Механизмы накопления металлов водорослями до конца не изучены, но чаще всего их связывают с высоким содержанием полисахаридов, для которых характерны ионообменные процессы, активно протекающие у альгиновых кислот и других полисахаридов водорослей [1]. Механизм накопления элементов из морской воды в водорослях имеет не только биохимическую, но и физико-химическую природу. Так, в работах Камнева [25] и Иванова [26] показана способность обмениваться некоторыми элементами с водой даже у мертвых водорослей.

Содержание элементов для двух семейств бурых водорослей (ламинариевые и фукусовые) значительно различается. Эта тенденция к различной степени накопления большинства элементов сохраняется в каждой точке отбора проб. При этом внутри одного семейства характерны сравнительно близкие значения содержания макро- и микроэлементов.

Такие элементы, как железо, магний, кальций, сера, кремний и алюминий в большей степени накапливаются фукусовыми водорослями, а накопление йода, титана, калия и хлора более выражено в ламинариевых водорослях (табл. 3). Сильных различий в накоплении брома, хрома, натрия, фосфора, стронция, цинка и меди между ламинариевыми и фукусовыми водорослями не наблюдается, а концентрации этих элементов в разных образцах водорослей различаются незначительно. Единственное, что следует отметить, это сильное превышение содержания фосфора в ламинариевых водорослях, отобранных в крайней северной точке маршрута экспедиции (остров Скотт-Келти, архипелага Земля Франца-Иосифа).

Из минеральных элементов наибольшую ценность представляют биогенные микро- и макроэлементы: калий, магний, кальций, железо, марганец, селен и др. Но наиболее важный элемент, содержащийся в бурых водорослях - йод [27]. В отличии от наземных растений и животных, которые содержат незначительные количества йода, в водорослях обнаруживаются значительные количества этого вещества [28]. В нашем исследовании были обнаружены концентрации йода от 0,148 до 0,619\% для ламинариевых водорослей и от 0 до 0,102\% для фукусовых (табл. 3). В образцах исследованных ламинариевых водорослей различий между накоплением йода не обнаружено, а из двух фукусовых водорослей накопление йода более выражено в образцах Ascophyllum nodosum. Однако следует отметить, что среднее содержание йода в образцах ламинариевых водорослей из Баренцева моря в 1,5 раза выше, чем в образцах, отобранных в Белом море (0,321 и 0,225\% соответственно). Это можно объяснить более высокой соленостью Баренцева моря по сравнению с Белым (табл. 1). В работе Коровкиной и др. [29] также отмечена положительная зависимость между соленостью и содержанием йода. Рекомендуемые нормы употребления йода 100-140 мкг в день для подростков и взрослых людей в районах, не страдающих дефицитом йода [30], а для йододефицитных районов - 180-200 мкг в день [31]. Следовательно, даже 1 г сушеных ламинариевых водорослей способен удовлетворить дневную потребность организма в йоде.

Таблица 2. Влияние солености морской воды на зольность водорослей*

\begin{tabular}{l|c|c|c|c}
\hline \multirow{2}{*}{ Область } & Средняя соленость воды & \multicolumn{3}{|c}{ Среднее содержание минеральных веществ, \% } \\
\cline { 3 - 5 } & в точках отбора проб & Laminaria saccharina & Laminaria digitata & Fucus vesiculosus \\
\hline Баренцево море & 34,0 & 30,82 & 29,49 & 22,57 \\
Белое море & 24,4 & 25,51 & 27,69 & 23,74 \\
\hline
\end{tabular}

* При расчете средней солености и средних значений содержания минеральных веществ точки отбора проб в зоне смешения водных масс Белого и Баренцева морей не учитывались (мыс Канин Нос и остров Сосновец). Среднее содержание минеральных веществ \pm 5 отн.\%, средняя соленость воды $\pm 0,5$ отн.\% 
Таблица 3. Содержание минеральных элементов в образцах бурых водорослей

\begin{tabular}{|c|c|c|c|c|c|c|c|c|c|c|c|c|c|c|c|c|c|c|c|c|}
\hline \multirow{2}{*}{ Проба } & \multirow{2}{*}{ Вид } & \multicolumn{18}{|c|}{ Содержание макро- и микроэлементов в биомассе БВ, \% от сухого вещества } & \multirow{2}{*}{$\begin{array}{c}\text { Зольность, } \\
\%\end{array}$} \\
\hline & & I & $\mathrm{Br}$ & $\mathrm{Fe}$ & $\mathrm{Cr}$ & $\mathrm{Ti}$ & $\mathrm{Mg}$ & $\mathrm{Na}$ & $\mathrm{Ca}$ & $\mathrm{K}$ & $\mathrm{Cl}$ & $\mathrm{S}$ & $\mathrm{P}$ & $\mathrm{Si}$ & $\mathrm{Sr}$ & $\mathrm{Zn}$ & $\mathrm{Cu}$ & $\mathrm{Al}$ & $\mathrm{Pb}$ & \\
\hline \multicolumn{21}{|c|}{ Баренцево море } \\
\hline \multirow{3}{*}{$\begin{array}{c}\text { Русская } \\
\text { Гавань }\end{array}$} & * & 335 & 0,108 & 0,052 & 0,030 & 0,032 & 0,787 & 5,09 & 458 & 9,946 & 13,984 & 1,228 & 0,31 & 0,331 & 0,062 & 0,007 & 0,014 & 0,068 & леды & 30,0 \\
\hline & 1.d.* & 0,267 & 0,084 & 0,041 & 0,029 & 0,023 & 0,623 & 3,327 & 1,019 & 9,826 & 11,616 & 1,181 & 0,273 & 0,171 & 0,059 & 0,008 & 0,008 & 0,030 & следы & 26,8 \\
\hline & f.v.* & 0,025 & 0,041 & 0,174 & 0,023 & 0,018 & 1,110 & 3,831 & 1,564 & 4,543 & 6,963 & 2,318 & 0,311 & 0,816 & 0,039 & 0,007 & 0,009 & 0,216 & следы & 20,9 \\
\hline \multirow{3}{*}{$\begin{array}{c}\text { Оранские } \\
\text { Острова }\end{array}$} & 1.s. & 0,179 & 0,177 & 0,060 & - & 0,019 & 0,833 & 5,088 & 1,656 & 11,778 & 15,850 & 1,284 & 0,345 & 0,299 & 0,105 & 0,007 & 0,002 & 0,044 & 0,0002 & 29,4 \\
\hline & 1.d. & 0,420 & 0,115 & 0,040 & - & 0,036 & 0,734 & 3,659 & 1,356 & 11,957 & 14,772 & 1,199 & 0,312 & 0,355 & 0,102 & 0,006 & 0,002 & 0,030 & 0,0008 & 29,3 \\
\hline & f.v. & 0,093 & 0,081 & 0,260 & - & 0,016 & 1,180 & 4,841 & 1,432 & 7,362 & 11,407 & 2,190 & 0,398 & 0,929 & 0,070 & 0,007 & 0,002 & 0,106 & следы & 23,2 \\
\hline \multirow{2}{*}{$\begin{array}{l}\text { Остров } \\
\text { Скотт- } \\
\text { Келти }\end{array}$} & l.s. & 0,619 & 0,154 & 0,058 & 0,048 & 0,054 & 0,899 & 6,136 & 1,979 & 18,904 & 21,229 & 1,227 & 0,948 & 0,254 & 0,095 & 0,013 & 0,002 & 0,059 & следы & 41,1 \\
\hline & 1.d. & 0,345 & 0,200 & 0,067 & 0,052 & 0,035 & 1,203 & 6,658 & 2,195 & 19,7 & 22,762 & 1,828 & 1,1 & 0,2 & 0,102 & 0,017 & 0,015 & 0,037 & сле & 39,1 \\
\hline \multirow{3}{*}{$\begin{array}{c}\text { Мыс } \\
\text { Желания }\end{array}$} & 1.s. & 0,221 & 0,065 & 0,063 & 0,027 & 0,023 & 0,793 & 4,435 & 1,240 & 6,898 & 10,880 & 1,135 & 0,293 & 0,275 & 0,048 & 0,019 & 0,017 & 0,060 & 0,0004 & 24,2 \\
\hline & 1.d. & 0,356 & 0,075 & 0,051 & 0,026 & 0,088 & 0,809 & 3,382 & 1,197 & 6,754 & 8,946 & 1,434 & 0,308 & 0,151 & 0,074 & 0,009 & 0,009 & 0,027 & 0,0007 & 23,4 \\
\hline & f.v. & 0,034 & 0,066 & 0,207 & 0,028 & 0,023 & 1,140 & 4,068 & 2,290 & 4,543 & 7,765 & 2,204 & 0,351 & 1,124 & 0,058 & 0,012 & 0,013 & 0,249 & $\mathrm{H} / \mathrm{O}$ & 23,3 \\
\hline & l.s. & 0,148 & 0,061 & 0,032 & 0,030 & 0,016 & 0,743 & 3,977 & 1,356 & 7,049 & 10,585 & 0,698 & 0,19 & 0,121 & 0,052 & 0,013 & 0,010 & 0,027 & $\mathrm{H} / \mathrm{O}$ & 23,1 \\
\hline Канин Н & 1.d. & 0,315 & 0,121 & 0,065 & 0,033 & 0,031 & 0,996 & 5,020 & 1,684 & 10,634 & 13,756 & 1,640 & 0,299 & 0,248 & 0,112 & 0,007 & 0,016 & 0,049 & $\mathrm{H} / \mathrm{O}$ & 32,3 \\
\hline \multicolumn{21}{|c|}{ Белое море } \\
\hline \multirow{4}{*}{$\begin{array}{c}\text { Остров } \\
\text { Сосновец }\end{array}$} & l.s. & 0,209 & 0,147 & 0,043 & 0,040 & 0,020 & 1,174 & 6,037 & 2,063 & 15,011 & 18,413 & 1,630 & 0,316 & 0,131 & 0,071 & 0,007 & 0,004 & 0,012 & 0,0003 & 43,2 \\
\hline & 1.d. & 0,241 & 0,089 & 0,049 & 0,032 & 0,022 & 0,972 & 4,210 & 1,473 & 10,495 & 12,854 & 1,772 & 0,273 & 0,136 & 0,083 & 0,009 & 0,024 & 0,010 & следы & 31,5 \\
\hline & f.v. & 0,018 & 0,071 & 0,045 & 0,027 & 0,006 & 1,594 & 7,256 & 1,387 & 5,974 & 12,657 & 2,783 & 0,273 & 0,188 & 0,065 & 0,018 & 0,014 & 0,027 & 0,0012 & 32,7 \\
\hline & a. $n *)$ & 0,102 & 0,141 & 0,102 & - & 0,015 & 1,203 & 4,598 & 1,916 & 6,415 & 9,761 & 2,976 & 0,295 & 0,510 & 0,106 & 0,018 & 0,005 & 0,044 & $\mathrm{H} / \mathrm{O}$ & 21,2 \\
\hline \multirow{4}{*}{$\begin{array}{c}\text { Остров } \\
\text { Большой } \\
\text { Соловец- } \\
\text { кий } \\
\end{array}$} & l.s. & 0,200 & 0,104 & 0,037 & 0,028 & 0,019 & 0,858 & 4,583 & 1,468 & 7,594 & 10,709 & 1,096 & 0,340 & 0,203 & 0,068 & 0,004 & 0,006 & 0,022 & 0,0002 & 21,6 \\
\hline & 1.d. & 0,197 & 0,101 & 0,036 & 0,029 & 0,019 & 0,851 & 3,961 & 1,536 & 8,996 & 11,134 & 1,673 & 0,270 & 0,134 & 0,094 & 0,008 & 0,005 & 0,014 & 0,0006 & 25,1 \\
\hline & f.v. & 0,058 & 0,067 & 0,104 & 0,026 & 0,014 & 1,446 & 5,755 & 1,527 & 5,158 & 8,806 & 2,320 & 0,227 & 0,388 & 0,066 & 0,004 & 0,018 & 0,061 & следы & 25,1 \\
\hline & a.n. & 0,058 & 0,180 & 0,103 & - & 0,015 & 1,422 & 4,060 & 2,208 & 5,427 & 5,610 & 3,295 & 0,296 & 0,562 & 0,086 & 0,006 & 0,002 & 0,080 & $\mathrm{H} / \mathrm{O}$ & 19,6 \\
\hline \multirow{4}{*}{$\begin{array}{c}\text { Остров } \\
\text { Русский } \\
\text { Кузов }\end{array}$} & 1.s. & 0,283 & 0,080 & 0,031 & - & 0,023 & 0,676 & 4,062 & 1,071 & 9,671 & 13,521 & 0,872 & 0,275 & 0,127 & 0,059 & 0,005 & 0,002 & 0,028 & $\mathrm{H} / \mathrm{O}$ & 29,4 \\
\hline & 1.d. & 0,224 & 0,141 & 0,051 & - & 0,021 & 0,982 & 4,590 & 1,859 & 11,400 & 14,365 & 1,838 & 0,386 & 0,511 & 0,159 & 0,004 & 0,002 & 0,039 & $\mathrm{H} / \mathrm{O}$ & 30,3 \\
\hline & f.v. & 0,000 & 0,073 & 0,082 & - & 0,007 & 1,764 & 8,750 & 1,787 & 5,521 & 14,017 & 2,498 & 0,228 & 0,336 & 0,085 & 0,004 & 0,002 & 0,059 & $\mathrm{H} / \mathrm{O}$ & 22,4 \\
\hline & a.n. & 0,017 & 0,122 & 0,089 & - & 0,011 & 1,411 & 5,031 & 2,958 & 5,333 & 7,988 & 3,652 & 0,269 & 0,492 & 0,130 & 0,006 & 0,002 & 0,061 & $\mathrm{H} / \mathrm{O}$ & 21,2 \\
\hline \multirow{4}{*}{$\begin{array}{c}\text { Остров } \\
\text { Большой } \\
\text { Соловец- } \\
\text { кий** }\end{array}$} & 1.s. & 0,134 & 0,131 & 0,045 & 0,029 & 0,016 & 0,813 & 5,279 & 1,384 & 11,757 & 15,052 & 1,341 & 0,395 & 0,096 & 0,068 & 0,004 & 0,002 & 0,008 & $\mathrm{H} / \mathrm{O}$ & 19,9 \\
\hline & 1.d. & 0,153 & 0,109 & 0,030 & 0,029 & 0,014 & 1,053 & 5,565 & 1,421 & 11,763 & 13,649 & 2,117 & 0,466 & 0,155 & 0,112 & 0,005 & 0,002 & 0,021 & $\mathrm{H} / \mathrm{O}$ & 29,2 \\
\hline & f.v. & 0,000 & 0,087 & 0,076 & 0,021 & 0,007 & 1,059 & 5,289 & 1,844 & 4,502 & 6,443 & 2,468 & 0,311 & 0,525 & 0,109 & 0,004 & 0,004 & 0,077 & $\mathrm{H} / \mathrm{O}$ & 22,6 \\
\hline & a.n. & 0,003 & 0,122 & 0,056 & 0,029 & 0,009 & 1,518 & 5,635 & 2,723 & 4,953 & 7,244 & 3,664 & 0,338 & 0,390 & 0,137 & 0,007 & 0,006 & 0,048 & $\mathrm{H} / \mathrm{O}$ & 23,7 \\
\hline
\end{tabular}

* laminaria saccharina - 1.s.; laminaria digitata - 1.d.; fucus vesiculosus - f.v.; ascophyllum nodosum - a.n.

** Образцы, отобранные в июне 2011 г. 
Экологическое состояние мест произрастания бурых водорослей оценивалось по содержанию в биообразцах тяжелых металлов: свинца и ртути. Наиболее опасным для человека элементом из рассматриваемых в нашей работе является ртуть [7]. По результатам проведенного анализа образцов бурых водорослей установлено наличие лишь следов ртути, что не превышает нормативных показателей [32]. Свинец также является токсичным тяжелым металлом, часто встречающимся в зонах, подверженных антропогенному воздействию. В большинстве образцов данный элемент не был найден, однако в некоторых образцах были обнаружены концентрации от 0,0002 до 0,0012\%, что, впрочем, является слабым превышением естественного фона. Подобные результаты по содержанию свинца и ртути в образцах бурых водорослей из акватории Белого моря были получены в ходе исследования А.В. Подкорытовой и др. [10].

Несмотря на то, что существуют данные о положительной зависимости между содержанием ионов $\mathrm{Mg}^{2+}, \mathrm{Ca}^{2+}, \mathrm{K}^{+}$и $\mathrm{Na}^{+}$в воде и накоплением этих элементов в водорослях [1], в ходе наших исследований эти тенденции не проявились.

\section{Выводы}

Распределение макро- и микроэлементов в бурых водорослях, обладающих богатым минеральным составом, зависит в большей степени от семейства, к которому принадлежит водоросль, чем от места произрастания.

Антропогенное воздействие на акватории Белого и Баренцева морей не привело к заметной концентрации свинца и ртути в зоне произрастания бурых водорослей, следовательно, данные биообъекты пригодны для переработки и получения широкого спектра продукции.

\section{Список литературы}

1. Гудимов А.В. Промысловые и перспективные для использования водоросли и беспозвоночные Баренцева и Белого морей. Апатиты, 1998. С. 529-581.

2. Клочкова Н.Г., Березовская В.А.. Водоросли Камчатского шельфа. Распространение, биология, химический состав. Владивосток; Петропавловск-Камчатский, 1997. 155 с.

3. Lee F.A. Basic food chemistry. AVI Publishing Company, Inc., Westport, 1983. p. 430.

4. Jurkovic N., Kolb N., Colic I. Nutritive value of marine algae Laminaria japonica and Undaria pinnatifida // Nahrung. 1995. Vol. 39. Pp. 63-66.

5. Jimnez-Escrig A., Cambrodon I,. Nutritional evaluation and physiological effects of edible seaweeds // Archives Latino-American Nutrition. 1999. Vol. 49. Pp. 114-120.

6. Ruperez P. Mineral content of edible marine seaweeds // Food Chemistry. Vol. 79. Pp. 23-26.

7. Давыдова Л.С., Тагасов В.И. Тяжелые металлы как супертоксиканты 21 века. М., 2002. 140 с.

8. Physicians for Social Responsibility [электронный pecypc]: Heavy Metals, 2009. URl: http://www.psr.org/environment-and-health/confronting-toxics/heavy-metals/ (accessed June 2010).

9. Conti Marcelo Enrique et. all. Baseline Trace Metals in Seagrass, Algae, and Mollusks in a Southern Tyrrhenian Ecosystem (Linosa Island, Sicily) // Archives of Environmental Contamination and Toxicology. 2010. Vol. 58. Pp. 79-95.

10. Подкорытова А.В., Вафина Л.Х., Муравьева Е.А., Шарина 3.Н. Санитарно-гигиеническая характеристика бурых водорослей Белого и Баренцева морей // Рыбпром. 2009. №4. С. 33-39.

11. Ranjith J., Matthias R. Use of seaweeds for monitoring trace elements in coastal waters // Environmental Geochemistry and Health. 1996. Vol. 18. Pp. 63-68.

12. Чернова Е.Н., Сергеева О.С. Концентрации металлов в саргассовых водорослях из прибрежных вод залива Нячанг (Южно-Китайское море) // Биология моря. 2008. №1. С. 57-63.

13. Коженкова С.И., Христофорова Н.К., Чернова Е.Н. Долговременный мониторинг загрязнения морских вод северного Приморья тяжелыми металлами с помощью бурых водорослей // Экология. 2000. №3. С. 233-237.

14. Almela C., Algora S., et. all. Heavy Metal, Total Arsenic, and Inorganic Arsenic Contents of Algae Food Products // Journal of Agriculture and Food Chem. 2002. Vol. 50. Pp. 918-923.

15. Sam C.Y., Jong H.M., et. all. Determination of toxic and trace elements in algae by instrumental neutron activation analysis // Journal of Radioanalytical and Nuclear Chemistry. 1999. Vol. 240, N1. Pp. 95-100.

16. Romari's-Hortas V., Garcia-Sartal C., et. all. Characterization of Edible Seaweed Harvested on the Galician Coast (Northwestern Spain) Using Pattern Recognition Techniques and Major and Trace Element Data // Journal of Agriiculture and Food Chemistry. 2010. Vol. 58. Рp. 1986-1992.

17. ГОСТ 26927-86. Сырье и продукты пищевые. Метод определения ртути. Введ. 01.12.1986. М., 1986.14 с.

18. ГОСТ 26185-84. Водоросли морские, травы морские и продукты их переработки. Методы анализа. Введ. 01.01.1985. Дата издания 19.07.2010. М., 2010. 34 с.

19. ПНД Ф 14.1:2:4.167-2000. Методика измерений массовой концентрации катионов аммония, калия, натрия, лития, магния, стронция, бария и кальция в пробах питьевых, природных (в том числе минеральных), сточных 
вод методом капиллярного электрофореза с использованием системы капиллярного электрофореза «КАПЕЛЬ». М., 2011. 36 c.

20. Руководящий документ РД 52.10.744-2010. Массовая концентрация кремния в морской воде. Методика измерений фотометрическим методом в виде синей формы молибдокремневой кислоты. М., 2010. 14 с.

21. Руководящий документ РД 52.10.738-2010. Массовая концентрация фосфатов в морских водах. Методика измерений фотометрическим методом. М., 2010. 27 с.

22. Руководящий документ РД 52.10.740-2010. Массовая концентрация азота нитритного в морских водах. Методика измерений фотометрическим методом с реактивом Грисса. М., 2010. 24 с.

23. Руководящий документ РД 52.10.735-2010. Водородный показатель морских вод. Методика измерений потенциометрическим методом. М., 2010. 19 с.

24. Сауг Р., Уиттик А. Основы альгологии. М., 1990. 597 с.

25. Камнев А.Н. Структура и функции бурых водорослей. М., 1989. 200 с.

26. Иванов В.Г., Егоров В.Н., Рожанская Л.И. Обмен и накопление Zn водорослями // Материалы 3 Всесоюзного совещания по морской альгологии - макрофитобентосу. Киев, 1979. С. 51-52.

27. Medicinal uses of seaweeds: Updated from Gaia 2008 Conference Notes. Drum R.: Island Herbs., 2008. URL: http:// www.ryandrum.com/seaweeds.htm.

28. The Ultimate source for all nutrition and health related issues [электронный pecypc]: Is it possible to cure common diseases with simple nutrition. Saturday, June 28, 2008. URL: http://www.lewrockwell.com/miller/miller20.html.

29. Коровкина Н.В., Богданович Н.И., Кутакова Н.А. Исследование состава бурых водорослей Белого моря с целью дальнейшей переработки // Химия растительного сырья. 2007. №1. С. 59-64.

30. World Health Organization (WHO). Evaluation of Certain Food Additives and Contaminants, 33rd Report of the Joint FAO/WHO Expert Committee on Food Additives. WHO Technical Report Series 776, Geneva, Switzerland, 1989.

31. Deutsche Gesellschaft fmr Ernghrung, German Society of Nutrition (DGE). Referenzwerte fmr die ghrstoffzufuhr, 1st ed.; Umschau/Braus: Frankfurt am Main, Germany, 2000.

32. Санитарные правила и нормы СанПиН 2.3.2.1078-01. Гигиенические требования безопасности и пищевой ценности пищевых продуктов. М., 2001. 36 с.

Поступило в редакциюю 28 марта 2013 г.

После переработки 10 мая 2013 г.

Bogolitsyn K., Kaplitcin P.*, Kashina E., Ivanchenko N., Kokryatskaya N., Ovchinnikov D. PECULIARITIES OF THE MINERAL COMPOSITION OF THE BROWN ALGAE IN THE WHITE AND BARENTS SEAS

${ }^{\text {I}}$ Northern (Arctic) Federal University M.V. Lomonosov, Naberezhnaia Severnoi Dviny, 17, Arkhangelsk, 163002 (Rus-

sia),e-mail:tph@agtu.ru

${ }^{2}$ Institute of Ecological Problems of the North, Ural Branch of Russian Academy of Sciences, Naberezhnaia Severnoi

Dviny, 23, Arkhangelsk, 163002 (Russia), e-mail: dirnauka@iepn.ru

${ }^{3}$ Center for collective use of scientific equipment «Arctic», Severodvinskaia st., 14, Arkhangelsk, 163002 (Russia),

e-mail: a.kozhevnikov@agtu.ru

The contents of macro ( $\mathrm{Mg}, \mathrm{Na}, \mathrm{Ca}, \mathrm{K}, \mathrm{Cl}, \mathrm{S}$ ) and trace elements (I, Br, Fe, Cr, Ti, P, Si, Sr, Zn, Cu, Al), as well as toxic heavy metals $(\mathrm{Pb}, \mathrm{Hg})$ was analyzed in 25 samples of four brown algae (Laminaria saccharina (Linnaeus) J.V.Lamouroux, Laminaria digitata (Hudson) J.V.Lamouroux, Fucus vesiculosus Linnaeus, Ascophyllum nodosum (Linnaeus) Le Jolis), harvested during the complex research expedition "The Arctic Floating University 2012", in the White and Barents Seas. Conclusions are drawn on the patterns in the accumulation of elements in brown algae depending on family and growth conditions, and also regarding the nutritional value of brown algae.

Keywords: brown algae, macro elements, trace elements, heavy metals.

\section{References}

1. Gudimov A.V. Promyslovye i perspektivnye dlia ispol'zovaniia vodorosli i bespozvonochnye Barentseva i Belogo morei. [Fishing and promising to use algae and invertebrates in the Barents and White Seas.]. Apatity, 1998, pp. 529581. (in Russ.).

\footnotetext{
* Corresponding author.
} 
2. Klochkova N.G., Berezovskaia V.A. Vodorosli kamchatskogo shel'fa. Rasprostranenie, biologiia, khimicheskii sostav [Algae Kamchatka shelf. Distribution, biology, chemistry.]. Vladivostok; Petropavlovsk-Kamchatsky, 1997, 155 p. (in Russ.).

3. Lee F.A. Basic food chemistry. AVI Publishing Company, Inc., Westport, 1983. p. 430.

4. Jurkovic N., Kolb N., Colic I. Nahrung, 1995, vol. 39, pp. 63-66.

5. Jimnez-Escrig A., Cambrodon I. Archives Latino-American Nutrition, 1999, vol. 49, pp. 114-120.

6. Ruperez P. Food Chemistry, vol. 79, pp. 23-26.

7. Davydova L.S., Tagasov V.I. Tiazhelye metally kak supertoksikanty 21 veka. [Heavy metals as supertoxicants $21 \mathrm{st}$ century.]. Moscow, 2002, 140 p. (in Russ.).

8. Physicians for Social Responsibility: Heavy Metals, 2009. URl: http://www.psr.org/environment-andhealth/confronting-toxics/heavy-metals/ (accessed June 2010).

9. Conti Marcelo Enrique et. all. Archives of Environmental Contamination and Toxicology, 2010, vol. 58, [p. 79-95.

10. Podkorytova A.V., Vafina L.Kh., Murav'eva E.A., Sharina Z.N. Rybprom, 2009, no. 4, pp. 33-39. (in Russ.).

11. Ranjith J., Matthias R. Environmental Geochemistry and Health, 1996, vol. 18, pp. 63-68.

12. Chernova E.N., Sergeeva O.S. Biologiia moria, 2008, no. 1, pp. 57-63. (in Russ.).

13. Kozhenkova S.I., Khristoforova N.K., Chernova E.N. Ekologiia, 2000, no. 3, pp. 233-237. (in Russ.).

14. Almela C., Algora S. et. all. Journal of Agriculture and Food Chem., 2002, vol. 50, pp. 918-923.

15. Sam C.Y., Jong H.M. et. all. Journal of Radioanalytical and Nuclear Chemistry, 1999, vol. 240, no. 1, pp. 95-100.

16. Romari's-Hortas V., Garcia-Sartal C. et. all. Journal of Agriiculture and Food Chemistry, 2010, vol. 58, pp. $1986-1992$.

17. GOST 26927-86. Syr'e i produkty pishchevye. Metod opredeleniia rtuti. [State standard 26927-86. Raw materials and food products. Method for the determination of mercury.]. Moscow, 1986, 14 p. (in Russ.).

18. GOST 26185-84. Vodorosli morskie, travy morskie i produkty ikh pererabotki. Metody analiza. [State standard 2618584. Seaweeds, sea grass and their products. methods of analysis]. Moscow, 2010. 34 p. (in Russ.).

19. PND F 14.1:2:4.167-2000. Metodika izmerenii massovoi kontsentratsii kationov ammoniia, kaliia, natriia, litiia, magniia, strontsiia, bariia $i$ kal'tsiia $v$ probakh pit'evykh, prirodnykh (v tom chisle mineral'nykh), stochnykh vod metodom kapilliarnogo elektroforeza s ispol'zovaniem sistemy kapilliarnogo elektroforeza «KAPEL». [PND F 14.1:2:4.167-2000. Technique for measuring the mass concentration of the cations ammonium, potassium, sodium, of lithium, magnesium, strontium, barium and calcium in samples of drinking water, natural (including mineral) wastewater by capillary electrophoresis using a capillary electrophoresis system "droplets".]. Moscow, 2011. 36 p. (in Russ.).

20. RD 52.10.744-2010. Massovaia kontsentratsiia kremniia v morskoi vode. Metodika izmerenii fotometricheskim metodom v vide sinei formy molibdokremnevoi kisloty. [Guidance document 52.10.744-2010. Bulk silicon concentration in seawater. Technique for measuring the photometric method in the form of a blue molibdokremnevoy acid]. Moscow, 2010. 14 p. (in Russ.).

21. RD 52.10.738-2010. Massovaia kontsentratsiia fosfatov v morskikh vodakh. Metodika izmerenii fotometricheskim metodom. [Guidance Document 52.10.738-2010. Mass concentration of phosphate in marine waters. Methodology of measurements photometric method.]. Moscow, 2010. 27 p. (in Russ.).

22. RD 52.10.740-2010. Massovaia kontsentratsiia azota nitritnogo v morskikh vodakh. Metodika izmerenii fotometricheskim metodom s reaktivom Grissa. [Guidance Document 52.10.740-2010. Mass concentration of nitrite nitrogen in marine waters. Technique for measuring the photometric method with Griess reagent.]. Moscow, 2010. 24 p. (in Russ.).

23. RD 52.10.735-2010. Vodorodnyi pokazatel' morskikh vod. Metodika izmerenii poten-tsiometricheskim metodom. [Guidance Document 52.10.735-2010. Hydrogen index marine waters. Measurement technique tsiometricheskim potential method.]. Moscow, 2010, 19 p. (in Russ.).

24. Saut R., Uittik A. Osnovy al'gologii. [Basics algology]. Moscow, 1990, 597 p. (in Russ.).

25. Kamnev A.N. Struktura $i$ funktsii burykh vodoroslei. [Structure and function of kelp.]. Moscow, 1989. 200 p. (in Russ.).

26. Ivanov V.G., Egorov V.N., Rozhanskaia L.I. Materialy 3 Vsesoiuznogo soveshchaniia po morskoi al'gologii makrofitobentosu. [Materials 3-Union Conference on Marine algology - Macrophytobenthos.]. Kiev, 1979, pp. 5152. (in Russ.).

27. Medicinal uses of seaweeds: Updated from Gaia 2008 Conference Notes. Drum R.: Island Herbs., 2008. URL: http:// www.ryandrum.com/seaweeds.htm.

28. The Ultimate source for all nutrition and health related issues: Is it possible to cure common diseases with simple nutrition. Saturday, June 28, 2008. URL: http://www.lewrockwell.com/miller/miller20.html.

29. Korovkina N.V., Bogdanovich N.I., Kutakova N.A. Khimiia rastitel'nogo syr'ia, 2007, no. 1, pp. 59-64. (in Russ.).

30. World Health Organization (WHO). Evaluation of Certain Food Additives and Contaminants, 33rd Report of the Joint FAO/WHO Expert Committee on Food Additives. WHO Technical Report Series 776, Geneva, Switzerland, 1989.

31. Deutsche Gesellschaft fmr Ernghrung, German Society of Nutrition (DGE). Referenzwerte fmr die ghrstoffzufuhr, 1st ed.; Umschau/Braus: Frankfurt am Main, Germany, 2000.

32. SanPiN 2.3.2.1078-01. Gigienicheskie trebovaniia bezopasnosti i pishchevoi tsennosti pishchevykh produktov. [Sanitary rules and norms 2.3.2.1078-01. Hygienic safety and nutritional value of foods.]. Moscow, 2001, 36 p. (in Russ.). 